\title{
Photocatalytic visible-light active bismuth tungstate coatings deposited by reactive magnetron sputtering
}

\author{
M Ratova ${ }^{\mathrm{a}}$, GT West ${ }^{\mathrm{a}}$, PJ Kelly ${ }^{\mathrm{a}}$
}

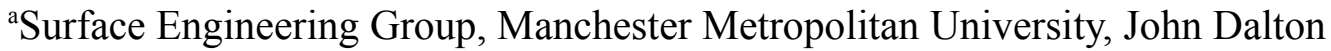

Building, Chester Street, Manchester M1 5GD, UK

Corresponding author: M Ratova, School of Engineering, Manchester Metropolitan University, John Dalton Building, Chester Street, Manchester M1 5GD, UK, tel. +44 161247 4648, e-mail address marina_ratova@hotmail.com

\begin{abstract}
Photocatalytic bismuth tungstate thin films with visible-light activity were deposited via reactive pulsed DC magnetron sputtering onto soda-lime glass substrates. Varying the power delivered to the bismuth and tungsten targets allowed control over the $\mathrm{Bi} / \mathrm{W}$ ratio in the coatings, and therefore the structural and optical properties of the coatings. Asdeposited coatings were characterised with amorphous microstructures and were annealed at $673 \mathrm{~K}$ to develop crystallinity. The visible light photocatalytic activity of the coatings, which was analysed using the methylene blue degradation test, was found to be superior to that of a commercial titania-based photocatalytic product. $\backslash$
\end{abstract}

\section{Keywords}

Bismuth tungstate; magnetron sputtering; photocatalytic coatings; visible light activity; methylene blue. 


\section{Main text}

In the past decade photocatalysis as a promising method of air and water decontamination has gained worldwide recognition[1-3]. Titanium dioxide, or titania, is the most used photocatalyst, since the pioneering work of Fujishima and Honda in 1969[4]. The wide use of $\mathrm{TiO}_{2}$ as a photocatalystis due to its stability, non-toxicity and low cost. However, there are several drawbacks associated with the use of $\mathrm{TiO}_{2}$ as a photocatalyst. Firstly, titanium dioxide exhibits low quantum efficiency due to fast recombination of photogenerated charge carriers. Secondly, titania is only efficient as photocatalyst when activated using a UV light source, due to its relatively high band gap value (3.2 eV for anatase). However, the fraction of UV irradiation is less than $5 \%$ of the solar spectrum; this number is even lower for indoor irradiation. Doping of titanium dioxide with various metallic and non-metallic elements allows this problem to be partly solved [5-7]; however doping of titania may result in the creation of extra recombination centres, and even faster recombination of photogenerated electrons and holes. Therefore, the advantages of doping are limited to some extent, and there is an obvious need for new solar-light activated photocatalytic materials with high quantum efficiency.

Bismuth complex oxides, such as molybdates, titanates and tungstates, have attracted some attention over the past few years as promising candidates for efficient solar-light activated photocatalytic materials[8-11]. The increasing number of publications shows that these materials have certain potential in replacing some titania-based photocatalysts. Bismuth complex oxidesare characterized with low band gap values, and consequently an ability to be activated with solar light, and high photocatalytic efficiency. Bismuth complex oxides are typically produced by such methods, as 
electrospinning [12], hydrothermal methods[13-15] or solid state reactions[16]. Of the various bismuth complex oxides studied, bismuth tungstate receives the most attention as a novel photocatalytic material with high visible light efficiency. Bismuth tungstate has been reported as an efficient photocatalyst for the degradation of organic dyes (methylene blue [17],rodhamine B [8, 11, 15, 17]), acetaldehyde [16, 18], and the inactivation of bacterial organisms, such as E.coli [19].

The present work describes for the first time the deposition of visible light active photocatalytic bismuth tungstate coatings, using pulsed DC reactive magnetron sputtering. Magnetron sputtering is a simple and scalable technique, widely used in both laboratories and industrial production facilities[20]. The main aim of this study was to evaluate the applicability of the reactive magnetron sputtering technique for the production of photocatalytic bismuth tungstate coatings.

All the coatings were deposited in a Teer UPD450 sputtering rig from two $300 \mathrm{~mm} \times$ $100 \mathrm{~mm}$ type II unbalanced planar magnetrons, installed through the chamber walls in a closed field configuration, as shown in Figure 1. The bismuth target was fitted on one of the magnetrons, and the tungsten target on the other one; both targets were $99.95 \%$ purity and bonded to copper backing plates. The reactive sputtering process was carried out in an argon/oxygen atmosphere at a pressure of 0.3 Pa. A dual channel Advanced Energy Pinnacle Plus power supply was used to drive the magnetrons at a frequency of $100 \mathrm{kHz}$ and $50 \%$ duty; powers to the targets were varied in the range of $100-400 \mathrm{~W}$ to vary the $\mathrm{Bi} / \mathrm{W}$ ratios in the coatings. The flows of oxygen and argon were controlled using mass-flow controllers (40 sccm of Ar and $28 \mathrm{sccm}$ of $\mathrm{O}_{2}$ ). Soda-lime glass slides, used as substrates, were ultrasonically pre-cleaned in propan-2-ol and mounted on a 
rotatable substrate holder at $100 \mathrm{~mm}$ distance from the targets. A rotation speed of $8 \mathrm{rpm}$ was used for deposition of all coatings.

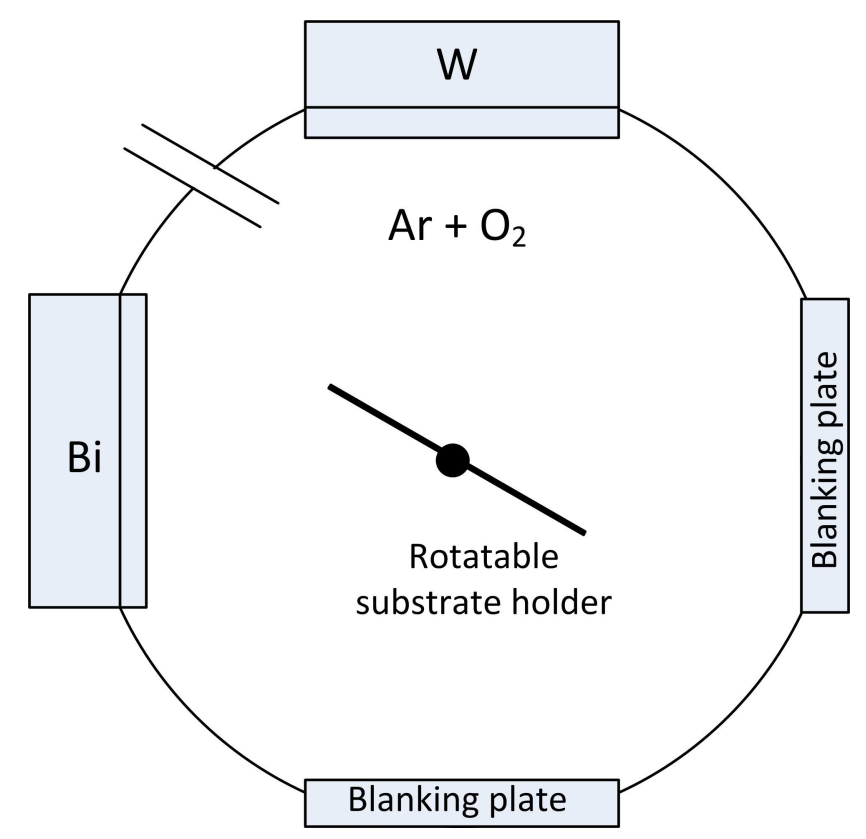

Figure . Schematic representation of Teer UDP450 sputtering rig

As all as-deposited coatings were amorphous, they were annealed in air at $673 \mathrm{~K}$ followed by gradual cooling (5-6 hours) to avoid thermal stress and delamination from substrate.

The thickness of the coatings was measured using a Dektak ${ }^{\mathrm{TM}}$ surface profilometry. The composition of the coatings was examined with EDX (EDAX - Trident). The crystallinity information was obtained with X-ray diffraction (Panalytical Xpert powder with $\mathrm{CuK} \alpha_{1}$ radiation at $0.154 \mathrm{~nm}$ in grazing incidence mode at $3^{\circ}$ ). MicroXAM white light surface profilometry was used for surface roughness measurements. The band gap values of the coatings were calculated using the Tauc plot method and transmittance data of the coatings was determined using an Ocean Optics USB 2000+ spectrometer. 
The assessment of photocatalytic properties was carried out using the methylene blue (MB) degradation test on samples of identical size $\left(2.5 \times 1.5 \mathrm{~cm}^{2}\right)$. Methylene blue was chosen as a model dye for convenience of comparison of this study to the earlier works in the field. The experimental setup and testing conditions were identical to the one described elsewhere [21, 22]. Similarly to the previously published work[22], the visible light source was simulated by combining fluorescent light tubes $(2 \times 15 \mathrm{~W}$ Philips) with a $395 \mathrm{~nm}$ long pass filter (Knight Optical, UK) to block the UV component. As methylene blue discoloration under the visible light can be caused by side reactions, as well as by photocatalytic degradation [23], reference tests were carried out prior to coatings examination. Thus, a blank sample (piece of soda-lime glass of identical size) was testedin methylene blue under the visible light source; additionally, each sample was tested in dark conditions. The absorbance value of the MB solution did not change more than $1 \%$ as the result of the experiments above; therefore these values were neglected in further calculations of photocatalytic activity. The results of photocatalytic measurements were compared to those for a sample of commercial photocatalytic coating of the same geometrical size, tested under identical conditions. The overview of the deposited coatings is given in Table 1.

Table . Compositional properties of bismuth tungstate coatings

\begin{tabular}{|l|l|l|l|l|}
\hline Sample ID & Power on Bi & Power on W & At.\% Bi/at. & Coating \\
& target, W & target, W & $\% \mathrm{~W}$ & thickness, \\
& & & & $\mathrm{nm}$ \\
\hline BiW1 & 300 & 150 & $94 / 6$ & 330 \\
\hline BiW2 & 200 & 200 & $86 / 14$ & 300 \\
\hline BiW3 & 150 & 300 & $67 / 33$ & 290 \\
\hline BiW4 & 100 & 400 & $47 / 53$ & 280 \\
\hline
\end{tabular}


The crystal structure of the coatings was determined by XRD, the patterns are shown in Figure 2. The patterns observed for coatings BiW1 and BiW2 correspond to a tetragonal sphaerobismoite structure of bismuth oxide $\mathrm{Bi}_{8} \mathrm{O}_{12}$ (JCPDS 96-901-2329). Coating BiW2 has several additional peaks corresponding to a crystalline orthorhombic russellite structure of bismuth tungstate $\mathrm{Bi}_{8} \mathrm{~W}_{4} \mathrm{O}_{24}(\mathrm{JCPDS}$ 96-901-1800). All diffraction peaks seen in the XRD pattern of coating BiW3 can be assigned to orthorhombic russellite, which is in a good agreement with the bismuth/tungsten content obtained by EDX and is consistent with results published by the other researchers[15]. The XRD pattern of coating BiW4 represents a mixture of orthorhombic russellite bismuth tungstate and tetragonal bismuth tungsten oxide $\mathrm{Bi}_{28} \mathrm{~W}_{2} \mathrm{O}_{48}$ (JCPDS 96-200-3106). 


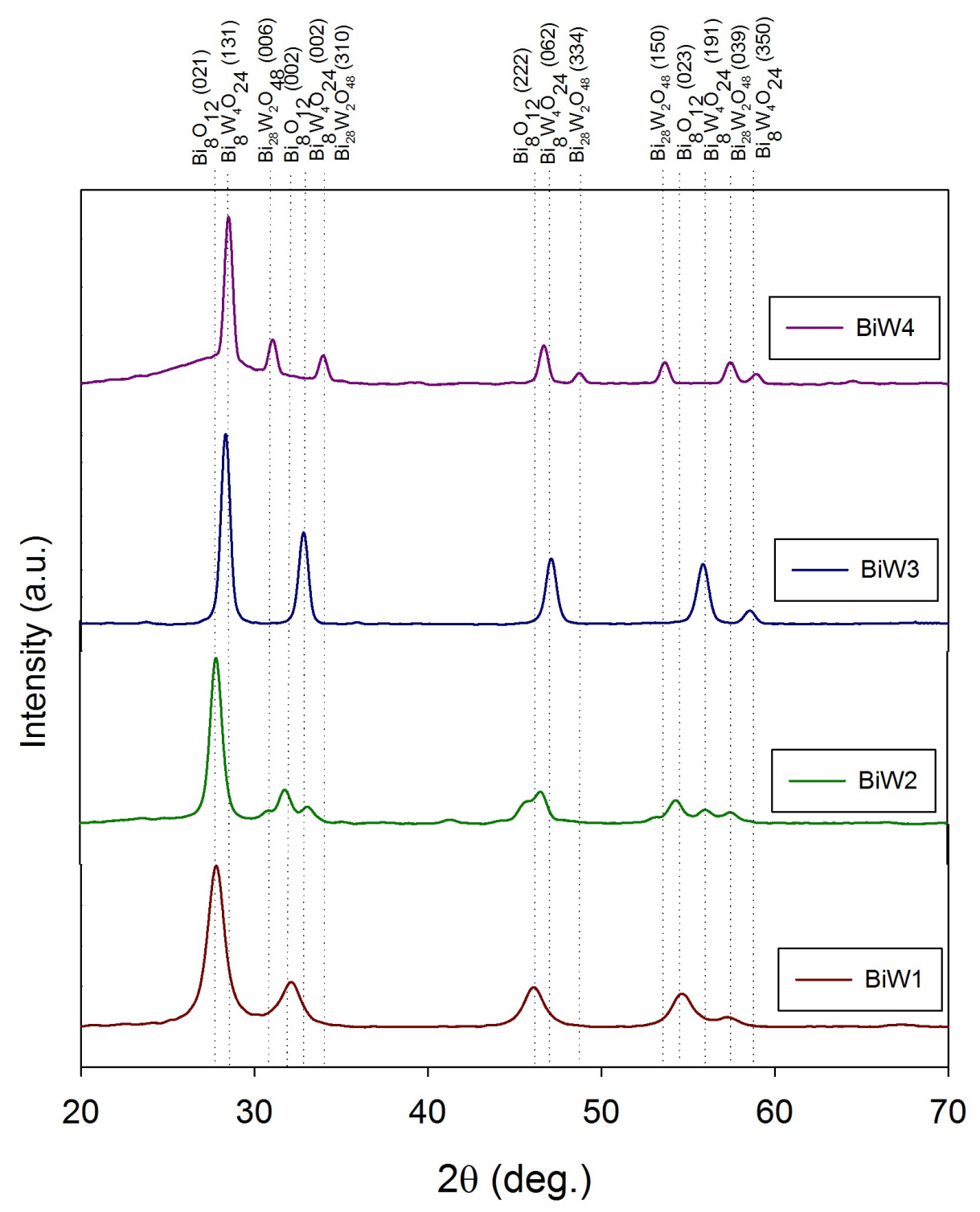

Figure. GIXRD patterns of samples BiW1-BiW4 annealed at 673K

Optical band gap values of the coatings were calculated using the Tauc plot method [24]. Band gaps were calculated using the coating transmittance data and plotting $(\alpha h v)^{1 / n}$ versus $h v$ and extrapolating the linear region of the plot to the abscissa (here $\alpha$ is the absorbance coefficient; $h$ is Planck's constant; $v$ is a vibration frequency; $n$ is an exponent that denotes the nature of the sample's transition). In this work, band gaps were estimated assuming indirect allowed transition, similarly to Amano et al. [18], therefore $n=2$. 
The summary of information for the annealed coatings, including their crystallinity, band gap values, surface roughness and results of the photocatalytic tests, is given in Table 2. Confirming the indirect allowed transition assumption, the band gap values calculated for the coatings are in good agreement with literature sources, where the band gap of magnetron sputtered bismuth oxide thin films is typically reported to be around $2.5 \mathrm{eV}[25]$ - this value is close to the band gaps of coatings BiW1 and BiW2.

Reportedly, the band gap values of bismuth tungstate (with $\mathrm{Bi} / \mathrm{W}=2$ ) vary from 2.6 to $2.8 \mathrm{eV}$, depending on the preparation method $[14,18]$, which is a good match with a value of $2.76 \mathrm{eV}$ for sample BiW3.

The surface roughness of the coatings was evaluated using the white light profilometry; all the produced coatings, as well as a sample of commercial photocatalytic coating Pilkington Activ ${ }^{\circledR}\left(S_{a}=12.6 \mathrm{~nm}\right)$, were of similar surface roughness, therefore their photocatalytic activities could be compared directly and different levels of the MB degradation observed under the visible light source should be attributed to compositional and optical properties of the coatings, rather than a variation in surface area.

The values of the first order rate constants of the MB degradation reaction are given in the Table 2 and graphically presented in the Figure 3. Though several reports found to date show that bismuth oxide shows some photocatalytic properties $[25,26]$, the visible light photocatalytic activity of samples BiW1 and BiW2, containing bismuth oxide as thepredominant crystal phase, was found to be rather low. These samples did not show evidence of crystalline bismuth-tungsten compounds, which raises the possibility of an amorphous phase containing tungsten being present. This could promote recombination of generated charge carriers, and hence a reduced photocatalytic activity, although this 
is speculative in the absence of more definitive evidence of amorphous material. Of the samples tested, the maximum activity was detected for bismuth tungstate sample BiW3. A decrease in $\mathrm{Bi} / \mathrm{W}$ ratio in coating BiW4 resulted in a considerably higher band gap value, and therefore lower rate of MB decomposition under the visible light source. Being a titania-based coating, the sample of commercial photocatalytic glass Activ ${ }^{\circledR}$ showed a low level of photocatalytic activity under visible light.

Table 2. Overview of properties of bismuth tungstate coatings annealed at $673 \mathrm{~K}$

\begin{tabular}{|c|c|c|c|c|}
\hline Sample ID & $\begin{array}{l}\text { Predominant } \\
\text { crystal phase }\end{array}$ & Band gap, eV & $\begin{array}{l}\text { Surface } \\
\text { roughness } \mathrm{S}_{\mathrm{a}} \text {, } \\
\mathrm{nm}\end{array}$ & $\mathrm{k}_{\mathrm{a}} \times 10^{5}, \mathrm{~s}^{-1}$ \\
\hline BiW1 & $\begin{array}{l}\text { Bismuth oxide } \\
\mathrm{Bi}_{8} \mathrm{O}_{12}(021)\end{array}$ & 2.54 & 13.5 & 1.2 \\
\hline BiW2 & $\begin{array}{l}\text { Bismuth oxide } \\
\mathrm{Bi}_{8} \mathrm{O}_{12}(021)\end{array}$ & 2.65 & 12.9 & 1.6 \\
\hline BiW3 & $\begin{array}{l}\text { Russellite } \\
\text { bismuth } \\
\text { tungstate } \\
\mathrm{Bi}_{8} \mathrm{~W}_{4} \mathrm{O}_{24} \\
(131) \\
\end{array}$ & 2.76 & 13.2 & 2.6 \\
\hline BiW4 & $\begin{array}{l}\text { Russellite } \\
\text { bismuth } \\
\text { tungstate } \\
\mathrm{Bi}_{8} \mathrm{~W}_{4} \mathrm{O}_{24} \\
(131) \\
\end{array}$ & 3.04 & 13.8 & 1.1 \\
\hline
\end{tabular}




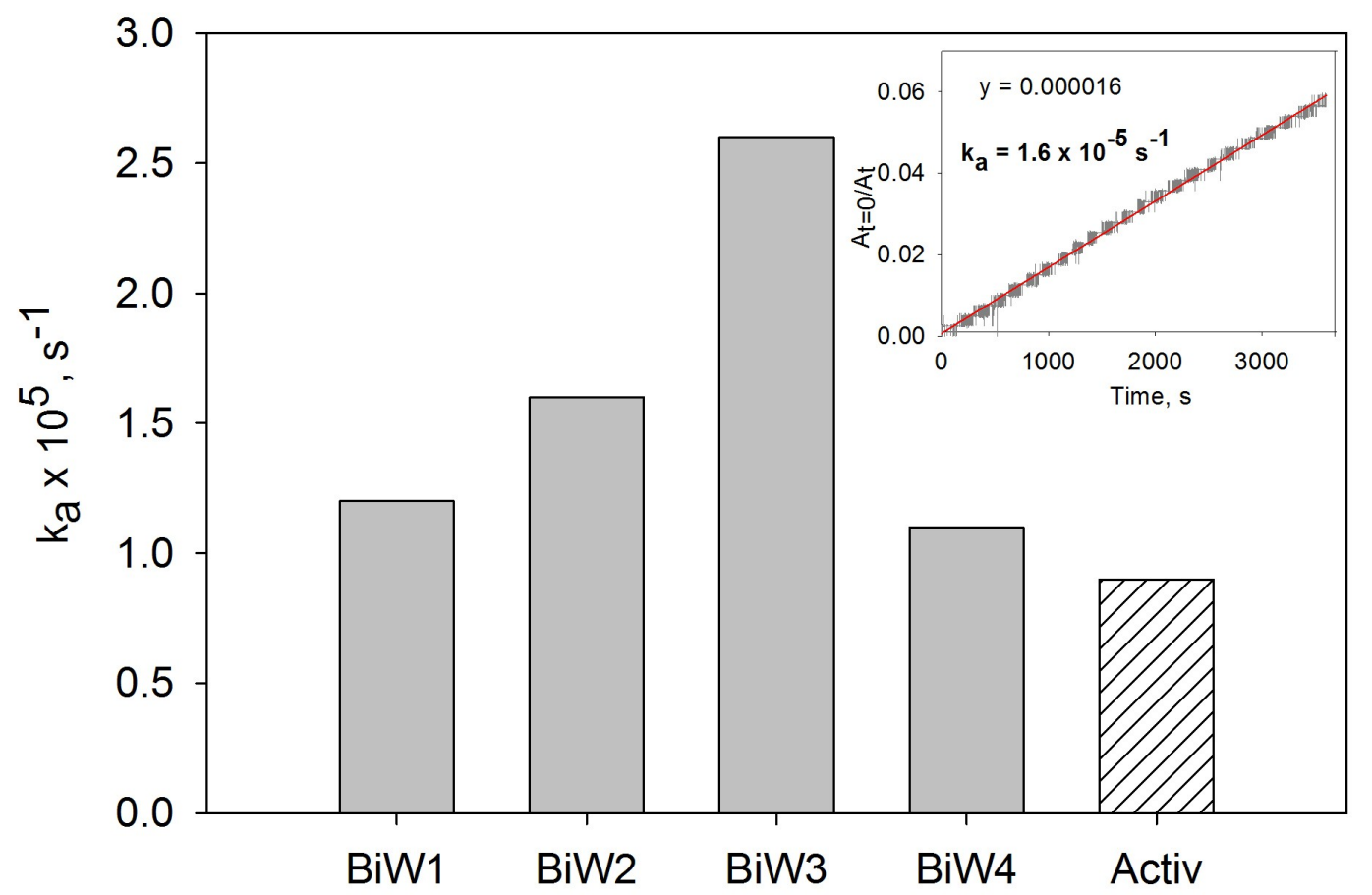

Figure . First order rate constants of MB photocatalytic degradation reaction under visible light and example of $\mathrm{k}_{\mathrm{a}}$ calculation for sample BiW2 (top right)

In summary, it was shown that the reactive magnetron sputtering method can be used for the deposition of bismuth tungstate thin films. Control ofthe power applied to the tungsten and bismuth targets allowed the content of these two elements in the coatings to be varied. Such variation had a significant effect on the optical and surface properties of the coatings. All coatings tested were characterised with lower band gap values, compared to anatasetitania coatings, typically used as photocatalysts, however a decrease in the $\mathrm{Bi} / \mathrm{W}$ ratio resulted in higher band gap values. Of the samples studied, the highest photocatalytic activity was observed for the coating with a $\mathrm{Bi} / \mathrm{W}$ ratio of 2 , which corresponds to the russellite crystal phase of bismuth tungstate, the most often reported as photocatalytically active. Taking into account the low surface roughness of 
the samples investigated, bismuth tungstate coatings deposited in this work showed good photocatalytic properties when being irradiated with visible light; their ability to degrade methylene blue dye was superior to that of the commercial photocatalytic sample (Activ ${ }^{\circledR}$ glass). It can be concluded that such coatings have a certain potential for production of photocatalytic products aimed at use indoors.

\section{References}

[1] Fujishima A, Zhang X. Titanium dioxide photocatalysis: present situation and future approaches. Comptes Rendus Chimie. 2006;9:750-60.

[2] Paz Y. Application of TiO2 photocatalysis for air treatment: Patents' overview. Applied Catalysis B: Environmental. 2010;99:448-60.

[3] Mills A, Le Hunte S. An overview of semiconductor photocatalysis. Journal of Photochemistry and Photobiology A: Chemistry. 1997;108:1-35.

[4] Fujishima A. HK, Kikuchi S. Photosensitized electrolytic oxidation on semiconducting n-type TiO2 electrode. Kogyo Kagaku Zasshi. 1969;72:108-13. [5] Farahani N, Kelly PJ, West G, Ratova M, Hill C, Vishnyakov V. Photocatalytic activity of reactively sputtered and directly sputtered titania coatings. Thin Solid Films. 2011;520:1464-9.

[6] Ratova M, Kelly PJ, West GT, Iordanova I. Enhanced properties of magnetron sputtered photocatalytic coatings via transition metal doping. Surface and Coatings Technology. 2013;228, Supplement 1:S544-S9.

[7] Ratova M, West GT, Kelly PJ, Xia X, Gao Y. Synergistic effect of doping with nitrogen and molybdenum on the photocatalytic properties of thin titania films. Vacuum. 
[8] Saison T, Gras P, Chemin N, Chanéac C, Durupthy O, Brezová V, et al. New Insights into Bi2WO6 Properties as a Visible-Light Photocatalyst. The Journal of Physical Chemistry C. 2013;117:22656-66.

[9] Li H, Liu C, Li K, Wang H. Preparation, characterization and photocatalytic properties of nanoplate Bi2MoO6 catalysts. J Mater Sci. 2008;43:7026-34.

[10] Hou J, Jiao S, Zhu H, Kumar RV. Facile synthesis and visible-light photocatalytic activity of bismuth titanate nanorods. J Nanopart Res. 2011;13:5557-64.

[11] Zhang L, Zhu Y. A review of controllable synthesis and enhancement of performances of bismuth tungstate visible-light-driven photocatalysts. Catalysis Science \& Technology. 2012;2:694-706.

[12] Zhao G, Liu S, Lu Q, Shi M, Song L. Preparation of Bi2WO6 by Electrospinning: Researching Their Synthesis Mechanism and Photocatalytic Activity. J Clust Sci. 2011;22:621-31.

[13] Lin X, Liu Z, Guo X, Liu C, Zhai H, Wang Q, et al. Controllable synthesis and photocatalytic activity of spherical, flower-like and nanofibrous bismuth tungstates. Materials Science and Engineering: B. 2014;188:35-42.

[14] Chu X, Shan G, Chang C, Fu Y, Yue L, Zhu L. Effective degradation of tetracycline by mesoporous Bi2WO6 under visible light irradiation. Front Environ Sci Eng. 2014:18 .

[15] Qamar M, Khan A. Mesoporous hierarchical bismuth tungstate as a highly efficient visible-light-driven photocatalyst. RSC Advances. 2014;4:9542-50.

[16] Tang J, Zou Z, Ye J. Photocatalytic Decomposition of Organic Contaminants by Bi2WO6 Under Visible Light Irradiation. Catalysis Letters. 2004;92:53-6. 
[17] Lu X, Peng Y, Han Z. Heterogeneous photocatalytic treatment of wastewater in ultraviolet light irradiation — photocatalyst Bi2WO6 microsphere with high repeatability. Front Optoelectron. 2012;5:439-44.

[18] Amano F, Nogami K, Ohtani B. Enhanced photocatalytic activity of bismuthtungsten mixed oxides for oxidative decomposition of acetaldehyde under visible light irradiation. Catalysis Communications. 2012;20:12-6.

[19] Helali S, Polo-López MI, Fernández-Ibáñez P, Ohtani B, Amano F, Malato S, et al. Solar photocatalysis: A green technology for E. coli contaminated water disinfection. Effect of concentration and different types of suspended catalyst. Journal of Photochemistry and Photobiology A: Chemistry. 2014;276:31-40.

[20] Kelly PJ, Arnell RD. Magnetron sputtering: a review of recent developments and applications. Vacuum. 2000;56:159-72.

[21] Ratova M, West G, Kelly P. Optimization Studies of Photocatalytic TungstenDoped Titania Coatings Deposited by Reactive Magnetron Co-Sputtering. Coatings. 2013;3:194-207.

[22] Ratova M, West GT, Kelly PJ. Visible light activated photocatalytic TaON coatings deposited via pulsed-DC magnetron sputtering. Vacuum. 2014;109:135-8.

[23] Mills A. An overview of the methylene blue ISO test for assessing the activities of photocatalytic films. Applied Catalysis B: Environmental. 2012;128:144-9.

[24] Tauc J, Grigorovici R, Vancu A. Optical Properties and Electronic Structure of Amorphous Germanium. physica status solidi (b). 1966;15:627-37.

[25] Sirota B, Reyes-Cuellar J, Kohli P, Wang L, McCarroll ME, Aouadi SM. Bismuth oxide photocatalytic nanostructures produced by magnetron sputtering deposition. Thin Solid Films. 2012;520:6118-23. 
[26] Weidong H, Wei Q, Xiaohong W, Xianbo D, Long C, Zhaohua J. The photocatalytic properties of bismuth oxide films prepared through the sols $\mathrm{h}^{\text {"ggel }}$ method. Thin Solid Films. 2007;515:5362-5. 